\title{
ANALYSIS OF HEIGHT MODELS BASED ON KOMPSAT-3 IMAGES
}

\author{
G. Büyüksalih ${ }^{1}$, S. Bayburt ${ }^{1}$, K. Jacobsen ${ }^{2}$ \\ ${ }^{1}$ BIMTAS, Istanbul, Turkey - serdar.bayburt@bimtas.istanbul, gurcan.buyuksalih@bimtas.istanbul, \\ serdar.bayburt@bimtas.istanbul \\ ${ }^{2}$ Institute of Photogrammetry and GeoInformation, Leibniz University, Germany - jacobsen@ipi.uni-hannover.de
}

ICWG III/IVa

KEY WORDS: Kompsat-3, image geometry, height model, SGM, area based matching

\begin{abstract}
:
Height models are basic information required for disaster Management. Not in any case satisfying and actual height models are available, but they can be generated by satellite stereo pairs being more precise as InSAR.

The Korean Kompsat-3 has a ground sampling distance of $0.71 \mathrm{~m}$. A stereo combination covering the main part of Istanbul has been used for the generation of height models. Kompsat-3 images are available as L1R images, corresponding close to the original image geometry, and as L1G, being projected to the SRTM 3 arcsec height model. For use of Semi Global Matching quasi epipolar images are required. They can be produced by just rotating the L1G-images to the stereo base, while with L1R-images requires at first a projection to a constant height level. The projection of L1G to the SRTM height models leads to height differences against the SRTM heights. The orientation of the L1R images with 71 ground control points (GCP) was possible in X and Y with 0.6 GSD and in Z with $1.1 \mathrm{GSD}$, while with L1G images only $1.2 \mathrm{GSD}$ respectively 2.9 GSD have been reached. A standard deviation of $0.6 \mathrm{GSD}$ for $\mathrm{X}$ and $\mathrm{Y}$ and $1.1 \mathrm{GSD}$ for $\mathrm{Z}$ is satisfying and a usual accuracy for satellite images. A comparison of the generated height model based on the L1G-images with airborne LiDAR data (ALS) showed clear local systematic height errors of the height model based on L1G-images which could not be seen with L1R-images.

The area based least squares matching leads to good results in open areas while in build up areas no accurate building determination is possible. Here SGM has a clear advantage with accurate roof structures corresponding to the $0.71 \mathrm{~m}$ GSD. For the relative accuracy, that means the building height and the roof structure, it does not matter if L1G or L1R images are used.
\end{abstract}

\section{INTRODUCTION}

Height models with satisfying geometric and morphologic accuracy, showing the actual situation, are a basic requirement for disaster mapping. They are required for the analysis of flooding, flood simulation but also as additional information after earthquakes and for forest fire prediction. Of course national height models are available, but not everywhere corresponding to the requirements, in addition the actual situation after the disaster case may be required and this can be achieved faster based on space information as with traditional aerial data acquisition.

Digital surface models (DSM) are also available free of charge as nearly worldwide DSM from SRTM, ASTER GDEM2 and AW3D30. These height models have a point spacing of one arcsec, corresponding to approximately $30 \mathrm{~m}$ at the equator. They have been investigated e.g. by Bayburt et al. 2017, Mukul et al. 2016, Takaku et al. 2014 and Tetsishi et al. 2014. ASTER GDEM2 has clearly the lowest accuracy of these three DSMs with a standard deviation in Z (SZ) in areas with a slope below $10 \%$ of approximately $6.3 \mathrm{~m}$, respectively a Normalized Median Absolute Deviation (NMAD) of 6.2m; SRTM follows with $\mathrm{SZ}=3.5 \mathrm{~m}$ and $\mathrm{NMAD}=2.9 \mathrm{~m}$ while $\mathrm{AW} 3 \mathrm{D} 30$ is slightly more accurate with $\mathrm{SZ}=2.6 \mathrm{~m}$ respectively $\mathrm{NMAD}=2.3 \mathrm{~m}$. Also the morphologic quality is the best for AW3D30. More morphologic details with $5 \mathrm{~m}$ point spacing are available with the commercial height model ALOS World 3D (AW3D), based on all available ALOS PRISM images having $2.5 \mathrm{~m}$ ground sampling distance (GSD). The Airbus DS WorldDEM, based on TanDEM-X Interferometric Synthetic Aperture Radar (InSAR) has $10 \mathrm{~m}$ point spacing and in open areas with terrain inclination below 10\% approximately 1m SZ (Wessel et al. 2018, Bayburt et al. 2017).

The accuracy in open areas with a terrain inclination below $10 \%$ of the WorldDEM corresponds to the expected accuracy to be achievable with a Kompsat-3 stereo model. But InSAR has some problems especially in urban and in very mountainous areas due to foreshortening and lay over. Especially in such an area height models based on optical images have some advantages. In addition area based matching justifies a point spacing of 3 pixels corresponding to $2.1 \mathrm{~m}$ for Kompsat-3 or even one pixel corresponding to $0.7 \mathrm{~m}$ for Semi Global Matching (SGM). Such a dense height model cannot be generated by InSAR. On the other side Differential InSAR (dInSAR) has the advantage of very precise determination of height changes as caused by earthquakes, but the volume determination of fast landslides, often caused by earthquakes, strong rain and flooding, cannot be determined by InSAR due to a complete change of the surface by a fast landslides. Finally height model determinations by radar and by optical images have special advantages, justifying the use of both technologies.

\section{GEOMETRY OF KOMPSAT-3 IMAGES}

The investigated KOMPSAT-3 stereo pair is available with the image products L1R and L1G. Corresponding to the Korean Aerospace Research Institute (KARI), level $1 \mathrm{R}$ is the product corrected for radiometric and sensor distortions, corresponding to Basic Imagery, while level $1 \mathrm{G}$ is the product corrected for geometric distortions and projected to UTM using the SRTM 3 arcsec height model version 4.1 (www.terranor.no./ImageData /KOMPSAT3_Image_Data_Manual_V1.2.pdf). The geolocation accuracy for the L1G projection is specified with 
40.6m CE90 needing an improvement by Ground Control Points (GCPs).

The image matching by SGM requires epipolar images. From satellite line scanner images quasi epipolar images can be generated by a simple rotation of Standard Images to the base direction of the stereo pair. Standard Images are a projection of the Basic Images to a plane with constant height, handled in the national coordinate system, usually UTM. L1G images projected to a rough height model also just have to be rotated to the base direction for getting quasi epipolar images, while L1R images (Basic Images) have to be projected before rotation to a plane with constant height - this corresponds to an ortho image with constant height.

By theory epipolar images are simpler to be generated with L1G images, not requiring the additional step of projection. On the other hand, height models generated by the standard method with $\mathrm{L} 1 \mathrm{G}$ images are leading to height differences in relation to the used SRTM DSM for generating L1G images and have to be corrected for the SRTM heights. This was also the case for QuickBird Standard Images. In the case of QuickBird the height correction by the reference SRTM DSM was leading to the same accuracy as with QuickBird Basic Images (Jacobsen 2006).

In the project area Istanbul 71 accurate and satisfying defined ground control points have been available. The image orientation by bias corrected Rational Polynomial Coefficients (RPC) has been done at first for the single L1G and L1R images and after this by three-dimensional orientation (tables 1 and 2).

\begin{tabular}{|l|c|c|c|c|}
\hline \multicolumn{5}{|c|}{ RPC orientation of single L1G images } \\
\hline image & SX & SY & $\begin{array}{c}\text { In view } \\
\text { direction }\end{array}$ & $\begin{array}{c}\text { Across view } \\
\text { direction }\end{array}$ \\
\hline 5935 & $0.95 \mathrm{~m}$ & $0.97 \mathrm{~m}$ & $1.03 \mathrm{~m}$ & $0.88 \mathrm{~m}$ \\
\hline 5820 & $0.84 \mathrm{~m}$ & $1.24 \mathrm{~m}$ & $1.29 \mathrm{~m}$ & $0.78 \mathrm{~m}$ \\
\hline \multicolumn{5}{|c|}{ Three dimensional orientation } \\
\hline \multicolumn{6}{|c|}{ SX } & SY & SZ \\
\hline Stereo model & \multicolumn{2}{|c|}{$0.82 \mathrm{~m}$} & $0.90 \mathrm{~m}$ & $2.07 \mathrm{~m}$ \\
\hline
\end{tabular}

Table 1. Accuracy of image orientation with Kompsat-3 L1G images determined with 71 ground control points;

$\mathrm{SX}=$ standard deviation of $\mathrm{X}, \mathrm{SY}=$ standard deviation of $\mathrm{Y}$

\begin{tabular}{|c|c|c|c|c|}
\hline \multicolumn{5}{|c|}{ RPC orientation of single L1R images } \\
\hline image & SX & SY & $\begin{array}{c}\text { In view } \\
\text { direction }\end{array}$ & $\begin{array}{c}\text { Across view } \\
\text { direction }\end{array}$ \\
\hline 5935 & $0.68 \mathrm{~m}$ & $0.67 \mathrm{~m}$ & $0.68 \mathrm{~m}$ & $0.67 \mathrm{~m}$ \\
\hline 5820 & $0.45 \mathrm{~m}$ & $0.40 \mathrm{~m}$ & $0.44 \mathrm{~m}$ & $0.41 \mathrm{~m}$ \\
\hline \multicolumn{5}{|c|}{ Three dimensional orientation } \\
\hline & & $\mathrm{X}$ & SY & SZ \\
\hline Stereo & & $3 \mathrm{~m}$ & $0.55 \mathrm{~m}$ & $1.09 \mathrm{~m}$ \\
\hline
\end{tabular}

Table 2. Accuracy of image orientation with Kompsat-3 L1R

It is obvious that the orientation of the L1G images (table 1) is not as accurate as the orientation of the L1R images (table 2) even with respected SRTM height values for L1G. In view direction uncertainties of the GCP height values are influencing the discrepancies, while across view direction height errors have no influence. The accuracy of the single L1G image orientation in view direction is clearly larger as across view direction, showing problems with the height reference. This cannot be caused by the height values of the GCPs as demonstrated by the L1R image orientation using the same GCPs (table 2). The L1R images are based on the same original images as the $\mathrm{L1G}$ images taken at March $23^{\text {rd }} 2017$. The orientation accuracy of the L1R images is within the expectation. The single image orientation in the average is 0.8 GSD corresponding to the GCP identification in the images. The three dimensional orientation with 0.76 GSD in $\mathrm{X}$ and $\mathrm{Y}$ is even slightly better and the height accuracy of 1.5 GSD can be explained by the base to height relation of $1: 1.23$ and the not stereoscopic measurement of the GCPs, enlarging by theory the discrepancies by $\sqrt{2}$. So finally the x-parallax component of the GCPs corresponds to $1.09 \mathrm{~m}$ $/ 0.71 \mathrm{~m} / 1.23 / \sqrt{ } 2=0.88 \mathrm{GSD}$ which is satisfying opposite to the L1G value of $1.68 \mathrm{GSD}$.

\section{GENERATION OF HEIGHT MODELS}

\subsection{Description of the stereo model}

With both Kompsat-3 image type height models have been generated by area based matching with least squares and region growing in combination with image pyramids and independent upon this by semi global matching. As reference a laser scanning height model with $5 \mathrm{~m}$ point spacing is available. Of course with $5 \mathrm{~m}$ point spacing the detailed digital surface model cannot be fully expressed in the densely build up area of Istanbul. In addition the height to base relation of 1:1.23 (figure 1) causes not negligible occlusions.

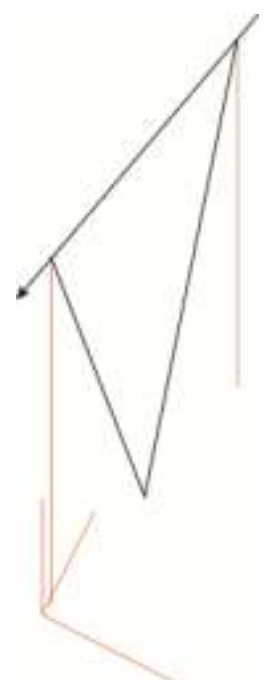

Figure 1. Viewing geometry of the used Kompsat-3 stereo model

Base to height relation $=$

$1: 1.23$

Roll angle $=0.14^{\circ}$, viewing to west

The roll angle of the stereo pair with $0.14^{\circ}$ is nearly optimal with an orbit footpath crossing the stereo scene. Streets across the orbit direction must have a width between the buildings of at least $80 \%$ of the building height to have a stereoscopic view of the street level and this usually is not the case in Istanbul, causing lacks of height information in street level. By simple theory the height accuracy corresponds to formula (1), but this does not respect the dependency of Spx from the height to base relation $\mathrm{h} / \mathrm{b}$. Experiences with other satellite images (Alobeid et al. 2006, Jacobsen et al. 2014) showed that a smaller angle of convergence leads to better similarity of the matched images and this reduces the standard deviation of the $\mathrm{x}$-parallax. So the dependency of the vertical accuracy is not so much depending upon the height to base relation, allowing the use of a smaller angle of convergence without real loss of accuracy, reducing the area of occlusion.

$S Z=S p x * h p b \quad$ (1) Theoretical accuracy relation of $\mathrm{x}-$ parallax (Spx) to the height accuracy (SZ) 


\subsection{Area based matching}

The problems with L1G images, as described above, are at least partially mentioned by KARI - they gave us the following information: "Actually, at the time of development of our processing S/W, "WGS84" was mentioned as vertical reference on description of SRTM DEM and 3 month later, USGS updated the geoid (maybe, EGM96) and we didn't recognize it." KARI mentioned to improve the L1G-product early 2018. This at least partially may explain the discrepancies of the image orientation and also the problems of the generated DSMs (figures 2 and 3).

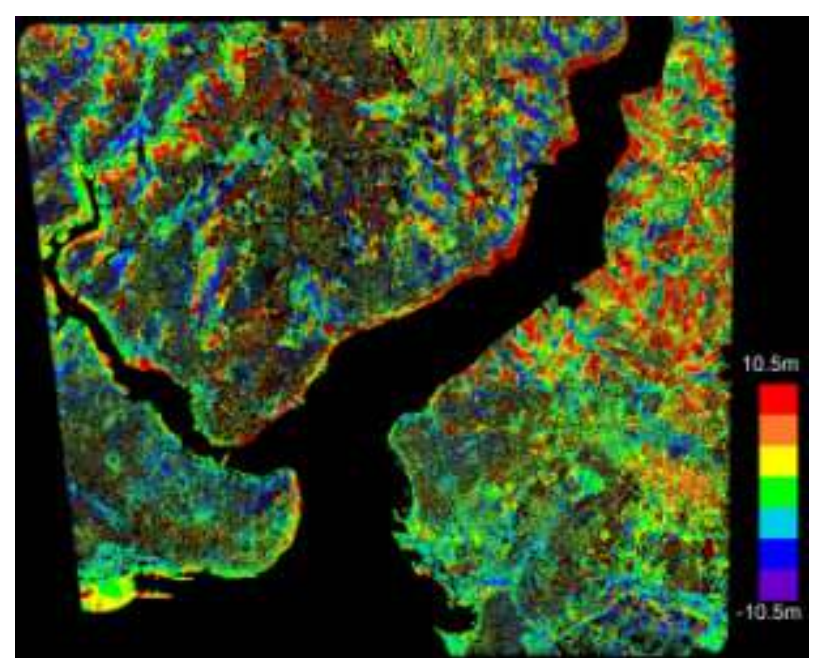

Figure 2. Colour coded height differences of Kompsat-3 L1G DSM against laser scanning reference

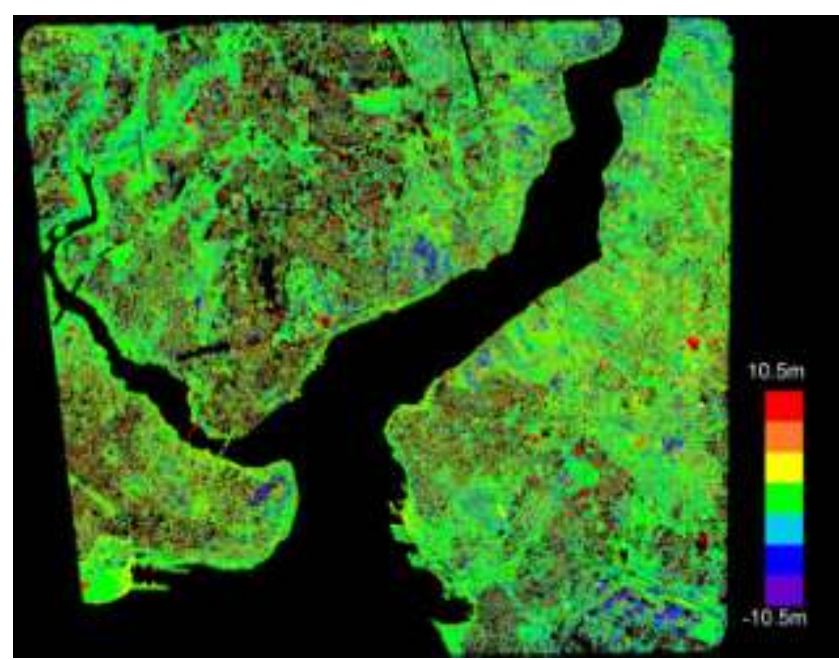

Figure 3. Colour coded height differences of Kompsat-3 L1R DSM against laser scanning reference

As first step a DSM has been generated by area based matching with least squares for the L1G and also the L1R stereo images. Colour coded height differences against the laser scanning reference DSM with $5 \mathrm{~m}$ point spacing are shown in figures 2 and 3. The geometric problems of the $\mathrm{L} 1 \mathrm{G}$ images are obvious. The problems visible in figures 2 and 3 are corresponding to the accuracy numbers in table 3 . The L1G results are clearly not as accurate as the L1R results. Of course the numerical comparison of the Kompsat-3 DSMs against the laser scanning reference is difficult due to the influence of the dense buildings. In addition the area based matching is smoothing the DSM, not showing the clear shape of the buildings. Nevertheless the accuracy relations are clear and close to the expectation.

\begin{tabular}{|c|c|c|c|}
\hline L1G & SZ & NMAD & SZ relative \\
\hline All points & $5.40 \mathrm{~m}$ & $4.80 \mathrm{~m}$ & $3.11 \mathrm{~m}$ \\
\hline Slope $<10 \%$ & $4.45 \mathrm{~m}$ & $3.60 \mathrm{~m}$ & \\
\hline F (slope) & \multicolumn{2}{|c|}{$\mathrm{SZ}=4.82+0.99 * \tan \mathrm{a}$} & $\mathrm{Z}=4.19+1.39 * \tan \mathrm{a}$ \\
\hline
\end{tabular}

\begin{tabular}{|c|c|c|c|}
\hline L1R & SZ & NMAD & SZ relative \\
\hline All points & $2.90 \mathrm{~m}$ & $2.34 \mathrm{~m}$ & $1.99 \mathrm{~m}$ \\
\hline Slope $<10 \%$ & $1.94 \mathrm{~m}$ & $1.20 \mathrm{~m}$ & \\
\hline $\mathrm{F}$ (slope) & \multicolumn{2}{|c|}{$\mathrm{SZ}=2.35+1.07 * \tan \mathrm{a}$} & $1.55 * \tan \mathrm{a}$ \\
\hline
\end{tabular}

Table 3. Comparison of Kompsat-3 DSM by area based matching with laser scanning reference DSM

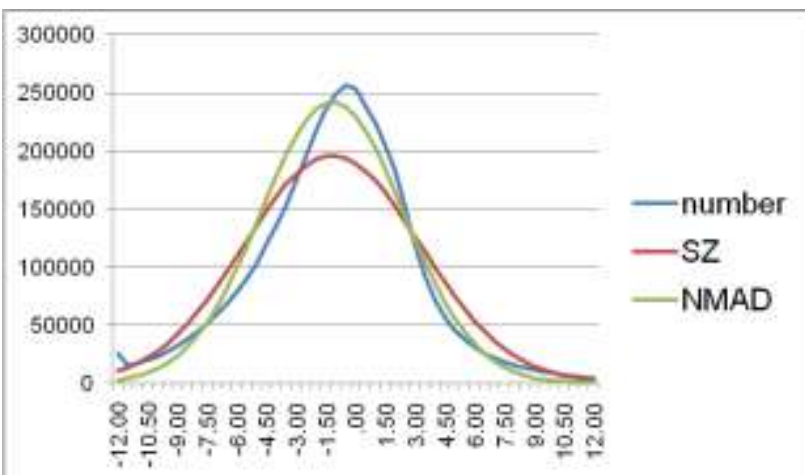

Figure 4. Frequency distribution of Z-discrepancies for areas with slope $<10 \%$ - Kompsat-3 L1G, overlaid with normal distribution based on SZ and NMAD; horizontal: discrepancies [m], vertical number of discrepancies in Z-group

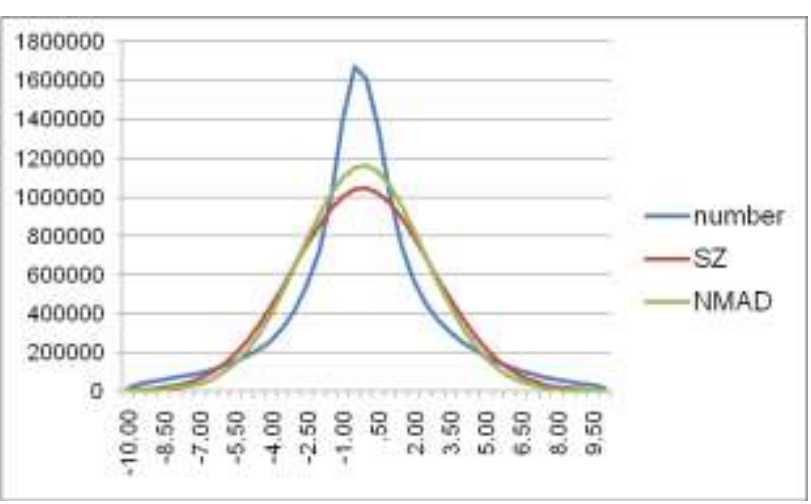

Figure 5. Frequency distribution of Z-discrepancies for areas with slope < 10\% - Kompsat-3 L1R; horizontal: discrepancies $[\mathrm{m}]$, vertical number of discrepancies in Z-group

Figures 4 and 5 are showing the frequency distributions of the Z-discrepancies between the DSM from area based matching and the reference laser scanning DSM for areas with a slope below 10\%. The lower accuracy of the L1G-data (figure 4) is influencing the whole frequency distribution. The kurtosis of 0.5 indicates a slightly higher number of larger discrepancies as the normal distribution. For the L1G-data with a kurtosis of 4.23 a clearly higher number of larger discrepancies as corresponding to the normal distribution are available. This at least partially is caused by larger discrepancies due to object changes between the laser scanning date and the date of taking the Kompsat-3 images shown as red spot e.g. at a football stadium, a new bridge over the Golden Horn and some new building complexes. In blue some negative discrepancies are shown in park areas, where the surface definition by laser 
scanning is not the same as for image matching. The kurtosis explains the difference between the standard deviation and the NMAD. NMAD is based on the median which is not so much influenced by large discrepancies as the standard deviation based on the square sum. As usual, the frequency distribution shows that NMAD describes the accuracy better as the standard deviation. Also as usual, the accuracy depends upon the terrain inclination corresponding to the function $\mathrm{SZ}=\mathrm{A}+\mathrm{B} *$ tangent (terrain slope). Under the not optimal conditions of object changes and different DSM description by laser scanning and by matching of optical images the NMAD for areas with a terrain inclination below $10 \%$ of $1.20 \mathrm{~m}$ is a satisfying result which is only slightly above SZ at GCPs (table 2).

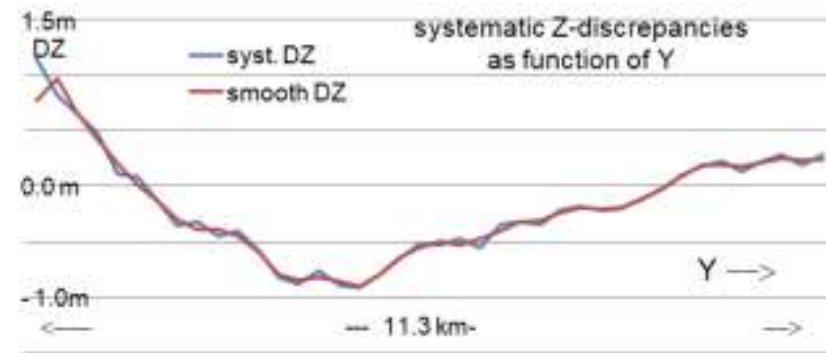

Figure 6. Systematic height differences as function of Y (L1R)

As for several optical satellite sensors (Jacobsen 2016) systematic height errors as function of Y-direction can be seen (figure 6). The systematic errors as function of Y (close to flight direction) can be determined also by means of the SRTM- or better the AW3D30-DSM. The model deformation is not negligible in relation to NMAD for slope below $10 \%$ of $1.20 \mathrm{~m}$ (table 3). A correction of the Kompsat-3 DSM by these systematic errors improved the accuracy values (table 4) to a NMAD for slope below $10 \%$ to $1.04 \mathrm{~m}$, corresponding to 1.46 GSD or the x-parallax to 1.2 GSD.

\begin{tabular}{|c|c|c|c|c|}
\hline L1R cor. & SZ & & $\mathrm{AD}$ & SZ relative \\
\hline All points & $2.59 \mathrm{~m}$ & & $2 \mathrm{~m}$ & $1.99 \mathrm{~m}$ \\
\hline Slope $<10 \%$ & $1.66 \mathrm{~m}$ & & $4 \mathrm{~m}$ & \\
\hline F (slope) & \multicolumn{2}{|c|}{$\mathrm{SZ}=2.12+0.67 * \tan \mathrm{a}$} & \multicolumn{2}{|c|}{$\mathrm{SZ}=1.63+1.06 * \tan \mathrm{a}$} \\
\hline
\end{tabular}

Table 4. Comparison of Kompsat-3 DSM based on area based matching with laser scanning reference DSM, corrected by systematic height errors as function of Y (figure 6)

\subsection{Semi Global Matching}

Semi Global Matching (Heinrichs et al. 2007) has the advantage of a pixel by pixel height determination, avoiding the DSM smoothing of area based matching. Of course it is also influenced by occlusions as discussed above. Nevertheless in the very densely build up area of Istanbul the roof structure has been determined well. Especially the roof of high buildings is not shown flat due to building furniture's on top.

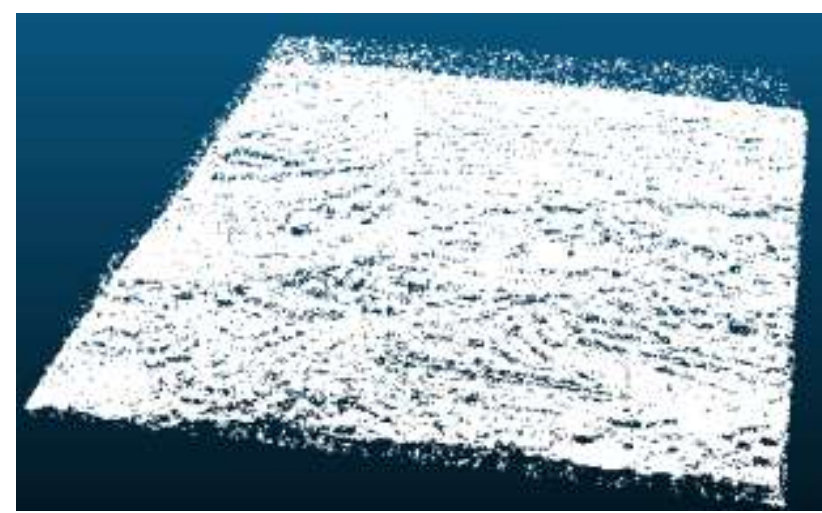

Figure 7. 3D-point cloud of SGM sub-area $1.4 \mathrm{~km} * 1.4 \mathrm{~km}$

The occlusions caused some noise (figure 7) which has been removed by a special three-dimensional neighbourhood filter. After filtering the SGM point cloud was satisfying. The comparison with the laser scanning reference with $5 \mathrm{~m}$ point spacing cannot correctly respect the facades. Due to the occlusion the facades in the height model are shown with some inclination causing height discrepancies (figures 10 and 11), so $\mathrm{SZ}$ reached $3.8 \mathrm{~m}$ also NMAD has a large value with $2.7 \mathrm{~m}$. Only in the area with a slope below $10 \%$, where the facades have no influence, NMAD reached $1.3 \mathrm{~m}$ but with a kurtosis of the frequency distribution of the height differences of 5.8, showing the influence of the terrain roughness by a higher number of larger discrepancies. Of course this is not a problem of the $\mathrm{SGM}$; it is a problem of the sudden height changes which cannot be described by the reference DSM with $5 \mathrm{~m}$ point spacing. The distribution of the height discrepancies (figure 8) shows large negative close to large positive height differences demonstrating the problems of this accuracy analysis.

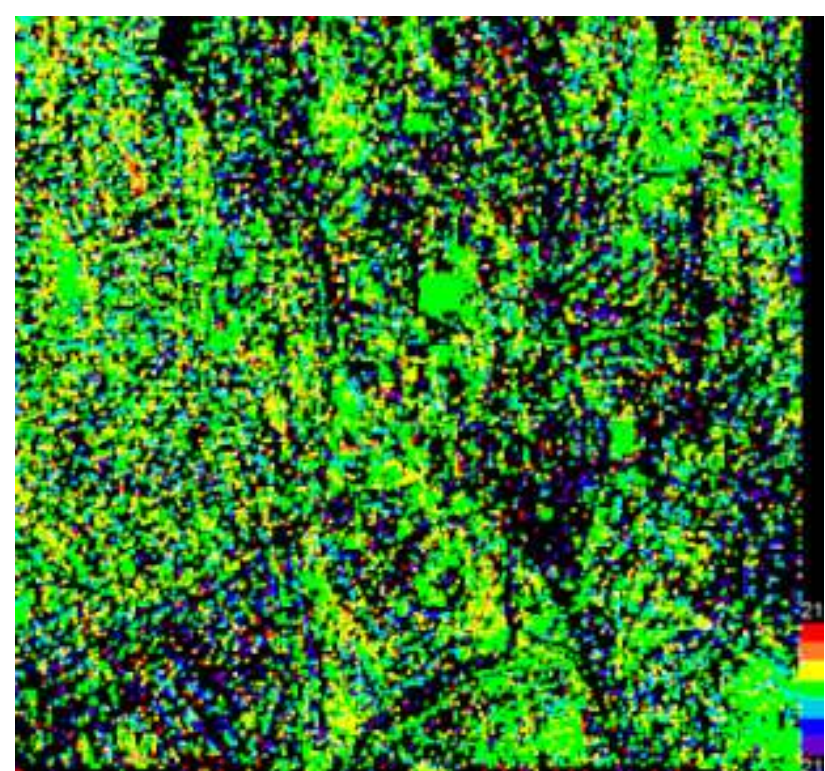

Figure 8. Colour coded height differences of SGM-point cloud against laser scanning reference

The colour coded SGM point cloud (figure 9) demonstrates the potential of the 3D-description in the densely build up area of Istanbul based on the Kompsat-3 stereo model. Not all buildings can be shown in figure 9 due to the limited resolution of the colour scale. 


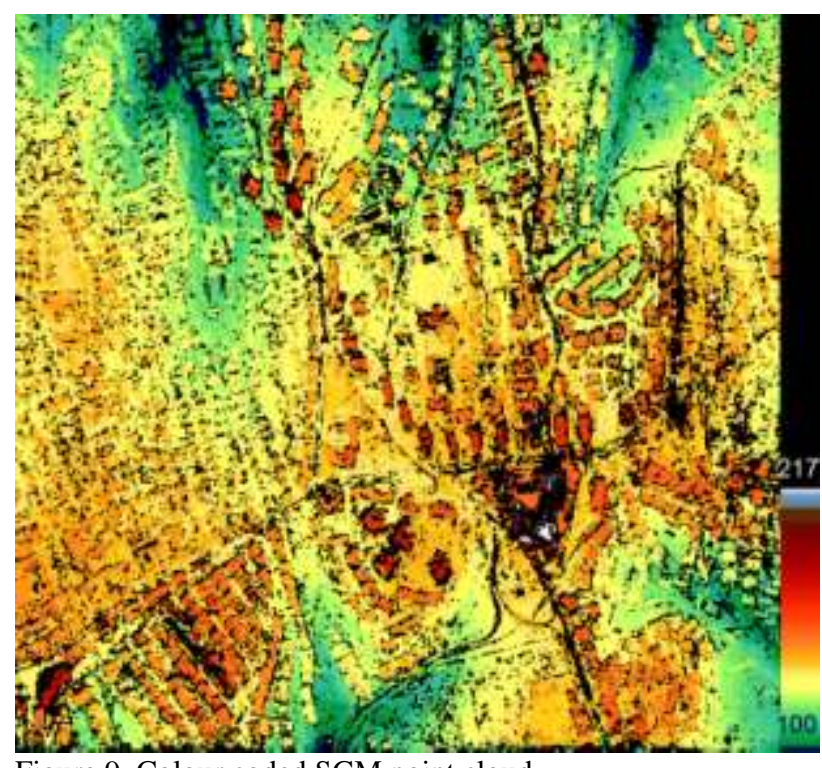

Figure 9. Colour coded SGM point cloud

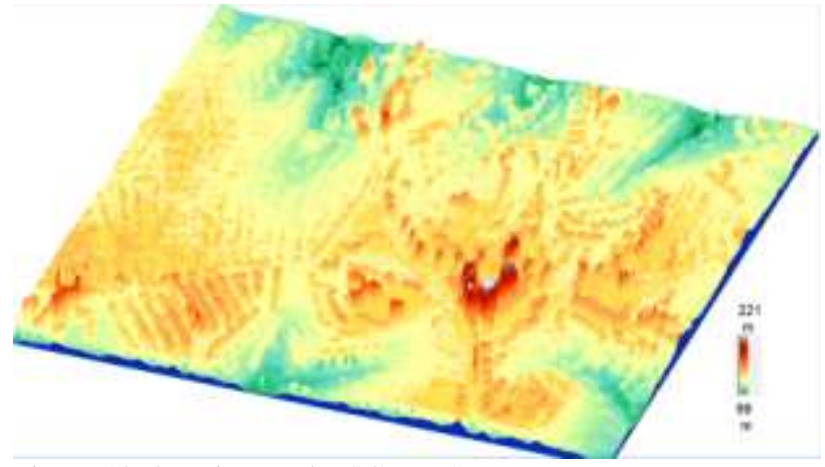

Figure 10. 3D-view to the SGM-DSM

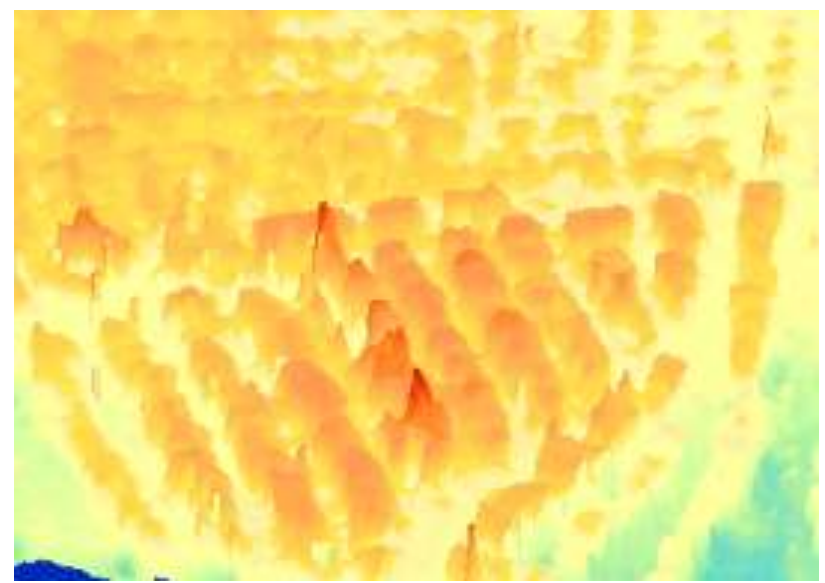

Figure 11. Detail of the 3D-view to the SGM-DSM

The 3D-view to the generated SGM-DSM (figures 10 and 11) show the potential and the limitation of the semi global matching with the $0.71 \mathrm{~m}$ GSD Kompsat- 3 stereo model with a base to height relation of $1: 1.23$. With a smaller angle of convergence of the stereo model the occlusions could be smaller, resulting in a better description of the buildings.

\section{CONCLUSION}

The generation of height models for disaster management is time critical, so the procedure has to be checked in advance. For Kompsat-3 images it became clear, that L1R images have to be used, at least before the announced improvement of the generation of this image product by KARI.

A smaller angle of convergence, corresponding to a smaller base to height relation, reducing the occlusion, would have some advantages for the height determination of the streets in the build up area. Nevertheless with the Kompsat-3 stereo pair satisfying results have been achieved. For getting a satisfying description of the $3 \mathrm{D}$ variation in such a densely build up area as Istanbul, the semi global matching has to be used. With the area based matching an overview to the height model can be generated, but this cannot describe the building details.

From the same area also a WorldView-4 stereo model is available. Of course with $31 \mathrm{~cm}$ GSD more details as with the $71 \mathrm{~cm}$ GSD of Kompsat-3 can be generated by semi global matching, but finally this is a question of economy and required details.

\section{REFERENCES}

Alobeid, A., Jacobsen, K., Heipke, C., 2009. Building height estimation in urban areas from very high resolution satellite stereo images, ISPRS Hannover Workshop 2009, IntArchPhRS. Vol XXXVIII-1-4-7/W5

Bayburt, S., Kurtak, A.B., Büyüksalih, G., Jacobsen, K., 2017. Geometric Accuracy Analysis of WorldDEM in Relation to AW3D30, SRTM and ASTER GDEM2, ISPRS Hannover Workshop 2017, ISPRS Archives - Volume XLII-1/W1, pp 211-217

Heinrichs, M., Rodehorst, V., Hellwich, O., 2007. ISPRS Archives - Volume XXXVI-3/W49A, 2007 Page(s) 185-190

Jacobsen, K., 2006. Comparison of Image Orientation by IKONOS, QuickBird and OrbView-3, EARSeL 2006, Warsaw, in "New Developments and Challenges in Remote Sensing", edited by Z. Bochenek, Millpress, Rotterdam 2007 ISBN 97890-5966-053-3, $667-676$

Jacobsen, K., Topan, H., Cam, A., Özendi, M., Oruc, M., 2014. Radiometric and Geometric Characteristics of Pleiades Images, ISPRS Com I symposium, Denver, ISPRS Archives - Volume XL-1, pp. 173-177

Jacobsen, K., 2016. Analysis and correction of systematic height model errors, ISPRS Archives - Volume XLI-B1, 333

Mukul, M., Srivastava V., Mukul, M., 2016. Accuracy analysis of the 2014-2015 Global Shuttle Radar Topography Mission (SRTM) 1 arc-sec C-Band height model using International Global Navigation Satellite System Service (IGS) Network, Journal of Earth System Science, Vol. 125, pp 909-917

Takaku, J., T. Tadono, K. Tsutsui. 2014. Generation of High Resolution Global DSM from ALOS PRISM, The International Archives of the Photogrammetry, Remote Sensing and Spatial Information Sciences, Volume XL-4, 2014

Tetsushi, T., et al., 2011. ASTER Global Digital Elevation Model Version 2 - Summary of Validation Results, http://www.jspacesystems.or.jp/ersdac/GDEM/ver2Validation/S ummary_GDEM2_validation_report_final.pdf (February 2018)

Wessel, B., Huber, M., Wohlfart, C., Marschalk, U., Kosmann, D. and Roth, A., 2018. Accuracy Assessment of the Global TanDEM-X Digital Elevation Model with GPS Data. ISPRS Journal of Photogrammetry and Remote Sensing 2018, pp 1-12 